NBER WORKING PAPER SERIES

\title{
CAPITAL LEVIES AND TRANSITION TO A CONSUMPTION TAX
}

\author{
Louis Kaplow \\ Working Paper 12259 \\ http://www.nber.org/papers/w12259
NATIONAL BUREAU OF ECONOMIC RESEARCH
1050 Massachusetts Avenue
Cambridge, MA 02138

May 2006

Harvard University and National Bureau of Economic Research. I am grateful to James Hines, Kyle Logue, Joel Slemrod, and other conference participants for comments, Mary Bear, Clifford Chen, Shelley de Alth, and Stephanie Gabor for research assistance, and to the John M. Olin Center for Law, Economics, and Business at Harvard University for financial support. This paper was prepared for "Key Issues in Public Finance: A Conference in Honor of David Bradford." My thinking about transitions has benefitted greatly from discussions with David over the course of more than two decades in connection with each of our prior writings on the subject. The current paper derives from a briefer treatment of capital levies and transitions in Kaplow (forthcoming). The views expressed herein are those of the author(s) and do not necessarily reflect the views of the National Bureau of Economic Research.

(O2006 by Louis Kaplow. All rights reserved. Short sections of text, not to exceed two paragraphs, may be quoted without explicit permission provided that full credit, including $\odot$ notice, is given to the source. 
Capital Levies and Transition to a Consumption Tax

Louis Kaplow

NBER Working Paper No. 12259

May 2006

JEL No. H21, H23, H24, H25, K34

\begin{abstract}
$\underline{\text { ABSTRACT }}$
The merits of capital levies depend on the likelihood of repetition, the extent of anticipation, and its effects on distribution. The relevance of these features, which in varying degrees is underdeveloped or underappreciated in pertinent literatures, is elaborated and then considered with regard to the problem of transition to a consumption tax. Other transition issues are distinguished, and specific attention is devoted to rate changes under a consumption tax and whether owners of preexisting capital are effectively compensated through higher net-of-tax returns due to repeal of the income tax. The analysis is also related to literature that examines dynamic models of taxation, particularly work simulating consumption tax transitions and assessing the optimality of capital taxation in the long run.

Louis Kaplow

Harvard Law School

Hauser 322

Cambridge, MA 02138

and NBER

moverholt@law.harvard.edu
\end{abstract}




\section{Introduction}

Transitions from one regime to another, whether involving taxation or other government policies, often result in substantial gains and losses to individuals on account of their preexisting investments. ${ }^{1}$ The extent of such losses, in turn, depends on the manner in which transitions are implemented, including whether they are accompanied by explicit forms of mitigation, ranging from windfall taxation and compensation to grandfathering and phase-ins.

The transition from an income tax to a consumption tax raises a broad spectrum of transition questions, many of which have been illuminated by David Bradford's (1996a, 1996b, 1998 , 2004) incisive and discerning mind. One issue that is especially important and somewhat distinctive is whether a consumption tax should be designed and enacted in a manner that results in a significant levy on preexisting capital. This particular aspect of the transition to a consumption tax is the focus of the present essay. Furthermore, the focus here is conceptual, being limited to the central question regarding the desirability of a consumption tax transition capital levy and thus abstracting from different forms of consumption taxation, interactions with other taxes, the treatment of businesses, aspects of implementation, effects on different types of assets and liabilities, transactions involving other taxing jurisdictions, the effects of inflation, the relevance of graduated rates, and many other issues. ${ }^{2}$ Likewise, no attempt is made to provide a careful analysis or empirical assessment of political economy questions, even though they are central to capital levies.

Section 2 elaborates three key features that determine the merits of capital levies. First is the likelihood of repetition, that is, whether a government's imposition of a capital levy will create the expectation of additional future levies, which would impose a large efficiency toll. Second is the extent to which a contemplated capital levy will be anticipated, for even if there would be no future repetition, a well-anticipated levy may be highly inefficient as well as ineffectual. Third is the distributive effect of the levy, which is pertinent to a full assessment of the welfare consequences and, relatedly, to comparisons with other means of raising revenue. In varying degrees, these elements are not fully understood and appreciated, so explicit attention is warranted.

Section 3 briefly overviews the general problem of transitions. Its central purpose is to differentiate among the various transition issues raised by moving to a consumption tax. Specifically, intended incentive effects - incentives attributable to living in the long run under a consumption tax rather than an income tax - are distinguished from accounting effects, the latter of which give rise to the possibility of a capital levy as part of a consumption tax transition.

${ }^{1}$ On transitions generally (and for more complete references to the wider literature), see, for example, Kaplow (1986, 1987, 2003) and Shaviro (2000).

${ }^{2}$ For previous discussions of the transition to a consumption tax, many of which consider a broader range of issues, see, for example, the works of David Bradford cited in the text, Kaplow (1986, 1995, 2003), Sarkar and Zodrow (1993), Shaviro (2000), Zodrow (2002), and also the literature discussed in section 5. 
Section 4 examines the transition to a consumption tax. Considered first is the relationship between transition to a consumption tax and imposition of a capital levy, which discussion draws on section 3's examination of accounting effects. Next, the three features of capital levies elaborated in section 2 are examined with regard to a consumption tax transition capital levy. Additional topics include: what would constitute full relief for such a capital levy, how the analysis extends to rate changes under a consumption tax, and whether owners of preexisting capital should be understood to be compensated for a consumption tax transition capital levy as a consequence of the higher net-of-tax return to capital that results when the transition also involves removal of an existing income tax.

Section 5 uses the present analysis to clarify the implications of prior literature that examines dynamic models of taxation. Discussed first is work that simulates transition from an income tax to a consumption tax and contrasts the transition to a wage tax. As many are aware, the central difference is that the former is assumed to embody a capital levy that is taken to be absent in the latter. Second, the section explores models designed to determine the optimality of capital taxation in the long run. It is not widely recognized that these models are closely related to transition to a consumption or a wage tax and, in particular, that some of their features relate to capital levies.

\section{Capital Levies}

\subsection{Repetition}

The most familiar problem with capital levies is that of repetition. Supposing that a capital levy would be desirable today (notably, in light of the considerations to be raised in subsections 2.2 and 2.3), the same considerations may well indicate that it would also be desirable tomorrow, the next day, and so on. The prospect of such future levies, however, would be a substantial deterrent to subsequent capital accumulation, with highly deleterious efficiency consequences. In their seminal exposition of the time inconsistency problem, Kydland and Prescott (1977) explain that, accordingly, a majority group of workers may rationally choose a constitution that limits their power to expropriate capital. ${ }^{3}$

The relationship, however, between a present levy and future ones requires further specification. Why would a promise not to repeat the levy be credible? Supposing that it would not, why should prospective capital owners not expect a levy tomorrow even if no such levy is imposed today?

${ }^{3}$ Kydland and Prescott (1977) also mention areas where the government has been less successful in restraining itself, including the imposition of price controls and windfall taxes on oil companies when prices spike, the prospect of which discourages exploration and production, and coming to the aid (through infrastructure projects) of those who build on flood plains, which action they might have found unprofitable but for the expectation of subsequent assistance. 
In the absence of an effective formal constitutional prohibition, the limitation on capital levies seems premised on social understandings. ${ }^{4}$ Formally, one might suppose that society is engaged in a repeated game, with the status quo of no capital levies combined with robust private investment being maintained perhaps as a trigger-strategy equilibrium. ${ }^{5}$ More loosely, there may exist social norms against capital levies. In either case, the repetition concern supposes that implementation of a capital levy would be followed by a substantial period during which individuals would behave as if another such levy was imminent. Deviations may be interpreted as defections that per se warrant punishment. Additionally, they may reveal pertinent information, including that social norms, promises, and political forces protecting existing capital are weaker than previously believed.

Eichengreen (1990), following related work by Grossman and Van Huyck (1988), has suggested the possibility that capital levies might be successfully employed in limited circumstances. In these models, the government in essence promises to levy on capital only in certain, circumscribed, states of nature - ones in which a levy would be particularly valuable. Allowing an exception to a flat no-levy promise provides a sort of insurance. As long as the probability of a levy is sufficiently low, the pertinent states can clearly be identified when they arise, and the government indeed abstains from a levy and fully pays its debt in all other states, it is possible to maintain an equilibrium in which there is little ex ante cost from discouraging investment. This formulation is concordant with Kydland and Prescott's (1977) concluding suggestion in favor of institutions that make deviations difficult in all but emergencies.

Eichengreen (1990) also presents a fascinating historical examination of capital levies, focusing particularly on extensive discussions of the possibility in the aftermath of World War I. Interestingly, the subject received (initially favorable) attention, even entire books, from leading economists of the day, including Dalton, Edgeworth, Hicks, and Pigou. Although offering various qualifications, Eichengreen (1990, p. 193) "finds virtually no examples of successful peacetime capital levies." ${ }^{6}$ His explanation relates to the problem of repetition as well as that of anticipation, the subject of the next subsection.

\subsection{Anticipation}

Another difficulty with capital levies, one that is occasionally emphasized but often forgotten, is anticipation. Even assuming that the government can credibly commit never to

${ }^{4}$ In the United States, there exist constitutional provisions against ex post facto laws and takings of property without compensation. These and other proscriptions, however, have not in modern times been interpreted to significantly constrain the government's taxing powers.

${ }^{5}$ See Friedman (1971).

${ }^{6} \mathrm{He}$ does mention that in some instances, although capital levies were rejected, modest capital income taxes were imposed, but the latter can be viewed as modest capital levies, although of a less efficient form. See subsection 5.2. Additionally, he mentions instances of hyperinflation which, to the extent unanticipated, is similar to a capital levy on public debt (including money). 
repeat a capital levy, the initial levy will be inefficient and substantially ineffectual to the extent that individuals anticipate its imposition. Consider, for example, a government that was expected to impose a capital levy ten years in the future. The effect on investment in the interim period would be much like that after a capital levy if repetition were expected ten years later. Consumption would be accelerated, long-term investment would be avoided, and capital flight and other forms of avoidance would be encouraged. Moreover, to the extent that these means were successful, there would be little capital on which to levy when the imposition became effective. Society would bear all the costs but receive little of the benefits.

Anticipation is a matter of degree. First, the length of the interim period will vary depending on the clarity of the forces leading to the imposition of a capital levy, the nature of government processes, and the content of the enactment (for example, a levy that is part of a substantive reform, such as the transition to a consumption tax, might be phased in over a period of time). Second and related, the probability of an impending levy may initially be low, generating limited avoidance, but subsequently rise. Some prospective levies may be largely ignored because they are believed to be overwhelmingly improbable, but as a levy becomes more realistic politically, greater response would be expected.

Eichengreen's (1990) reading of history is that largely unanticipated capital levies are extremely difficult to enact, particularly in modern democracies, since major action follows open, prolonged deliberation and political activity. As will be discussed further in subsection 4.2.2, this point seems especially pertinent to a capital levy that is imposed not in response to an emergency but as a consciously chosen policy designed to raise revenue or redistribute income. If a capital levy were to accompany a major tax reform, there would be prolonged periods of academic analysis, public discourse, government contemplation, and political debate and compromise prior to enactment. ${ }^{7}$ If one does not observe substantial reductions in investment during any of this period, the most plausible interpretation is that most individuals do not believe that reform - or, in particular, reform accompanied by a capital levy - is very likely. ${ }^{8}$

The exception that proves the rule is the actual imposition of a levy by the occupying authorities in Japan right after World War II: Action was swift and unaccompanied by public discussion. Additionally, it may not have given rise to a fear of repetition since it was imposed by outsiders, soon to depart, and was apparently motivated by a desire to expropriate from those believed to have contributed to the outbreak of war and to have profited from its execution.

Eichengreen (1990) seems somewhat sympathetic to the aforementioned levies proposed in the aftermath of World War I, if they could have been enacted quickly (which he doubts), following the theory that levies carefully limited to certain emergency situations may be

${ }^{7}$ Also, as noted, if enactment is not immediately (or, better yet from this perspective, retroactively) effective, but rather delayed, such as through a prolonged phase-in, there is additional time during which inefficient avoidance may take place.

${ }^{8}$ It would be interesting to investigate whether the openly discussed capital levies in the 1920 's had an impact on the market for public debt (the contemplated target). 
desirable. However, even if implemented swiftly at the conclusion of the war, there remains a substantial problem of anticipation. If it were accepted that governments could cancel their own debt after a successful war effort, individuals would be very reluctant to lend during wartime, which could be catastrophic. (And potential adversaries, knowing of such circumstances, would be more willing to attack.) For emergency exceptions of the sort described in subsection 2.1 to make sense, they must involve situations (say, a natural disaster) that investors do not anticipate with a high probability ex ante.

\subsection{Distribution}

The preceding two subsections focus on adverse effects due to the expectation of capital levies. If these problems are set to the side, it is ordinarily taken for granted that a capital levy would be desirable. Indeed, one-time capital levies are traditionally viewed as an ideal sort of tax because in principle they are nondistortionary. There is, however, a conceptual problem with this understanding because the distributive incidence of capital levies is also relevant to welfare.

To develop this point, observe that, in developed economies that have an income tax, one could raise sums distortion-free by reducing the grant component of the tax schedule, even making it negative - i.e., a uniform lump-sum levy. For example, in models with a linear income tax, one could raise the intercept and reduce the slope. The primary deterrent to using this approach is not inefficiency but dislike of the distributive consequences. If a capital levy is a mere substitute for lowering the uniform grant, and if the grant is already set optimally, then there is no benefit to a capital levy. And if the grant is not set optimally, one could simply adjust it.

A capital levy therefore is not appealing independently of its distributive consequences. Specifically, in a world in which all individuals were identical, a capital levy would raise problems of anticipation and repetition while offering no advantage over adjusting the uniform per capita grant. This point is especially striking because some work related to capital levies (see, for example, that discussed in subsection 5.2) is undertaken in a Ramsey setting with identical individuals, in which it is arbitrarily assumed that an income tax is unavailable.

It seems apparent, however, that a successful capital levy may nevertheless be welfareincreasing because of its indirect tendency to redistribute the fruits of labor effort without distorting labor supply. At any given point in time, ownership of the existing capital stock is distributed in a way that positively correlates with prior earnings and thus with underlying earning ability, for individuals' savings are the product of prior accumulations that ultimately

${ }^{9}$ Another example is Fischer (1980), who identifies the absence of a lump-sum tax instrument as the reason for the appeal of a capital levy but offers no explanation for why his model implicitly rules out this feature of a linear income tax. Criticism of the Ramsey framework along these lines originates in Atkinson and Stiglitz's (1976) seminal paper on optimal income and commodity taxation and is further discussed in Stiglitz (1987) and Kaplow (forthcoming). 
derive from labor income. (And to the extent ownership derives from inheritance, there is a positive intergenerational relationship between earnings of donors and donees.) The correlation will be highly imperfect due to differences in lifecycle stage, preferences, and other factors, although such confounding effects could be addressed, such as by making the levy age dependent. ${ }^{10}$ The point is that, although an optimal income tax can only redistribute at a distortionary cost, an idealized capital levy may accomplish some redistribution without distorting labor supply. ${ }^{11}$

Note that if capital levies are appealing because their incidence is correlated with labor earnings, there may be a better alternative: Current taxation of prior labor earnings. Analogous to a capital levy - in particular with regard to problems of anticipation and repetition - suppose that a tax was suddenly imposed that was an increasing function of prior years' earnings, or that the upcoming year's income tax payments were unexpectedly announced to be a function of preceding rather than current earnings. Such a scheme might achieve a substantially higher correlation between tax obligations and underlying earnings ability than would a capital levy, and thus be superior on distributive grounds (but equally nondistortionary). The possibility of making income tax payments explicitly a function of prior economic behavior has received some limited attention in the theoretical literature. ${ }^{12}$

\section{Transitions: A Brief Conceptual Overview}

Policy changes that are not fully anticipated tend to produce gains and losses regarding pre-enactment investments, raising the question whether some form of mitigation should be provided. The transition to a consumption tax was among the first to receive sustained attention by commentators. It was recognized that transition effects could arise in different ways and that losses from removal of a tax preference seemed distinguishable from losses due to the taxation of old capital that had previously been taxed under an income tax. Nevertheless, initially there was no framework delineating what sort of transition policy was optimal for various gains or losses, and no consensus existed regarding how much if any relief should be provided for different types of transition effects. Compare, for example, Bradford and U.S. Treasury (1984) with Graetz

${ }^{10}$ The lifecycle complication is especially important (and pertinent to the application in subsection 4.2.3 to the transition to a consumption tax). See also subsection 4.5. For example, a plain capital levy would redistribute from sixty-year-old school teachers who had saved a good deal to twenty-year-old future Bill Gates's. Another important factor bearing the incidence of a capital levy concerns its base, for example, whether it includes social security or pension wealth. A caveat is that, in a fully dynastic world in which all individuals were linked to those in prior and succeeding generations, the lifecycle effects would substantially offset across different generations.

${ }^{11}$ Rogers (1986) makes a different point regarding capital levies and distribution, namely that, to the extent a capital levy has undesirable distributive features, such levies may be discouraged, which would help alleviate the time inconsistency problem.

${ }^{12}$ See, for example, Roberts (1984). 
(1979).

Kaplow $(1986,1987)$ formulated the question as determining what transition policy maximizes social welfare under a range of assumptions, including that the transition policy will be anticipated ex ante and implemented ex post - i.e., with commitment rather than the time inconsistency problem. ${ }^{13}$ In answering the question, two types of transition effects were distinguished: intended incentive effects and accounting changes. This approach was employed extensively in Shaviro (2000) and subsequently explicated in Kaplow (2003), which also surveys much of the literature. Portions of the pertinent work address transitions generally, but from the beginning the framework has been applied to tax transitions, including the transition to a consumption tax.

To illustrate the distinction and see its relevance to transition policy, consider two simple reforms involving Pigouvian taxes. In the first, an externality has recently been identified, leading ultimately to the enactment of a first-best Pigouvian tax on the activity. Should owners of preexisting investments be exempted (grandfathered) or compensated, or should the tax be gradually phased in? Grandfathering or a phase-in would result in uncorrected (or not fully corrected) post-enactment behavior. Moreover, the anticipation effect of all three forms of relief would be disadvantageous, assuming that there was a positive ex ante probability that the externality existed (which seems especially likely as evidence mounts during the period preceding enactment). One way to state the idea is to recall that it is generally efficient for market actors to bear changes in real resource costs on account of changes in technology or demand and also that the role of Pigouvian taxation is to induce actors to incorporate real social costs due to externalities into the same market calculus.

Second, suppose that a Pigouvian tax had previously been imposed on the purchase of inputs that produce the externality, but it is subsequently decided that it is administratively convenient to impose the tax instead at the time the inputs are utilized in production. Should the inputs in inventory be taxed twice - once under the preexisting regime and again under the new regime - or should already-taxed inventory be exempt from the reformulated tax? If anticipated ex ante, the prospect of double taxation would inefficiently discourage productivity during the pertinent period. Likewise, if the opposite reform were to be contemplated - moving from a tax at the time of production to a tax on input purchases - failure to tax inventory at the time of transition would produce an inefficient surge in pre-enactment activity.

To recapitulate, the first example is what might be referred to as an intended incentive effect and the latter might aptly be characterized as an accounting change. The transition to a consumption tax, as already suggested, clearly involves many effects in the former category, and

${ }^{13}$ On account of risk aversion, mitigation would be optimal ex post, just as full insurance coverage for losses caused by nature or the market is optimal ex post. Another key assumption (relaxed in other parts of the analysis) is that the policy changes under consideration are optimal; however, because this postulate is primarily relevant to the sorts of transition effects not considered in this essay, it will not be elaborated further here. 
depending on the treatment of old capital, may have effects in the latter category as well. ${ }^{14}$ Because this essay is about the possibility of a levy on old capital, it is useful to offer some additional, tax-related examples of accounting changes.

The simplest example is the one initially presented in Kaplow (1986) to motivate the accounting change category. Suppose that tax was previously levied using an accounting year from July 1 to June 30 , and it is decided that it would reduce bookkeeping costs to move tax years to January 1 to December 31 . Without a transition adjustment, a six-month period will be double-taxed or omitted, and the anticipation thereof would produce a large distortion in the timing of economic activity. To avoid this problem requires a transitional accounting "year" of six or eighteen months, as the case may be. Note that if one went with the double-taxation transition, one would have a sort of capital levy (or an additional levy on past earned income), which would have the desirable features described in subsection 2.3, if one could avoid the problems of anticipation and repetition.

To take another example, suppose that all retirement plans under the income tax were in the style of Roth IRA's, that is, tax prepaid, and it was decided to switch to taxation at the time of consumption. Failure to exempt pre-existing retirement accounts would again result in double taxation. (Note that this example has features virtually identical to those due to the transition from a wage tax to a consumption tax, on which more below.) Likewise, one could have the reverse transition (analogous to the transition from a consumption tax to a wage tax). One could similarly envision switches between income taxes due currently (withholding and estimated tax payments required) and income taxes due only at the end of the year. In these cases as well, the analysis is similar to that of the capital levies explored in section 2: Distributive effects are likely to be desirable, but anticipation and repetition concerns may be serious.

Interestingly, in settings in which such accounting changes have occurred, it seems that single taxation is the norm. When fiscal years are changed, transitional accounting "years" are in fact employed to avoid double-taxation or no taxation. When Roth IRA's were created, old IRA's could not freely (i.e., without prepayment) be converted. If Roth IRA's were to be

\footnotetext{
${ }^{14}$ Effects in the former category include changes in the relative treatment of assets due to myriad imperfections in capital accounting (tax depreciation that does not match economic depreciation, expensing of some assets), the realization requirement, and differential tax rates for interest, dividends, and capital gains; changes due to the elimination of explicit tax preferences that may accompany such a reform; and changes with regard to imputed income (e.g., if housing is subject to the prepayment method under a consumption tax, so that the imputed rent from housing becomes effectively subject to tax). For prior treatments of these and other issues, see the literature cited in note 2 . Note that, as suggested by the two reforms involving Pigouvian taxes, the possible desirability of mitigating the effects of the accounting change aspect of transition to a consumption tax does not imply the desirability of mitigating otherwise-desirable incentive effects. In this regard, note that, as discussed in subsection 4.5, the prospect of present investment being subject to more neutral treatment in the future will induce more neutral - that is, less distorted - investment incentives prior to enactment.
} 
repealed, one strongly suspects that existing accounts will not thereby become subject to tax upon withdrawal. As will be discussed momentarily, however, double taxation would arise in precisely this manner under some means of transition from income taxation to consumption taxation.

\section{Transition to a Consumption Tax}

\subsection{Does a Consumption Tax Contain a Capital Levy? \\ 4.1.1. Consumption Taxes, Wage Taxes, and Income Taxes}

In a steady state, it is generally accepted that flat-rate wage and consumption taxes are equivalent. ${ }^{15}$ A wage tax reduces one's earnings by a given fraction, which has the effect of reducing subsequent purchasing power by the same fraction regardless of how one chooses to allocate earnings over time. And this latter effect is precisely what consumption taxation does directly, whether it is implemented as a cash-flow tax (earnings are taxed, savings are deducted, and withdrawals are taxed) or as a sales tax or VAT. For convenience, subsequent discussion will focus on forms of cash-flow consumption taxation, but analogous schemes generally exist for other variants.

As background, two main arguments have been offered in support of moving from an income tax to a consumption tax or a wage tax (apart from considerations of a capital levy). First, an income tax - in addition to distorting labor supply, as do a consumption tax and a wage tax - also distorts the intertemporal allocation of consumption by taxing the return to savings. ${ }^{16}$ As a consequence, individuals consume too much in early periods (save too little). ${ }^{17}$ Second,

${ }^{15}$ If the tax has graduated rates, there is no divergence if wages are uniform over time and individuals fully smooth consumption; otherwise, differences arise. Additionally, the text abstracts from uncertainty, which in idealized settings also does not affect the comparison. Finally, a consumption tax, being ex post, taxes inframarginal investment returns whereas a wage tax does not. These possible differences and others, however, are largely orthogonal to the present question concerning a capital levy.

${ }^{16}$ Although it is familiar that one cannot compare second-best policies simply by counting the number of distortions, under the assumption of weak separability of leisure, the optimal tax (or subsidy) on capital is zero in basic models with an income tax that distorts labor supply in the process of redistributing income. See Atkinson and Stiglitz (1976) and the generalization in Kaplow (2006). For further discussion and qualifications, see, for example, Stiglitz (1987) and Kaplow (forthcoming).

${ }^{17}$ As Feldstein (1978) emphasizes, the extent of distortion is not indicated by the change in savings but instead by the effect of differential taxation on consumption across periods. Note, for example, that even if savings were unaffected, it would still be true that future savings falls relative to present consumption as the tax on capital income increases. The key distinction is that savings (adjusted for the net-of-tax interest rate) indicates expenditures on future consumption, 
moving to a consumption tax or perhaps a wage tax is believed by many to produce significant administrative benefits, including the important side-effect of reducing inter-asset distortions that result from the difficulty of treating different types of capital uniformly under an income tax. This view was importantly advanced by Andrews (1974) and plays a substantial part in subsequent work by Bradford (e.g., 1986).

An important complication is that the present income tax is highly impure, really an awkward hybrid between an income tax and a consumption tax. Notably, retirement savings, consumer durables (including housing), human capital (in important respects), unrealized appreciation, and other assets are treated substantially as they would be under a consumption tax, although the lack of inflation adjustments and the existence of a corporate tax can increase the rate of taxation on capital. Furthermore, the continued deductibility of many types of interest produces an inconsistent system with opportunities for arbitrage. In aggregate, the actual system is probably a good distance toward a consumption tax already, although regarding administrative considerations many believe that the concomitant benefits of a consumption tax (or a purer income tax) would be particularly great. In any event, although these complications substantially affect the likely magnitude and distribution of any capital levy that might accompany a transition to a consumption tax, they do not affect its basic character and hence will be largely ignored hereafter. $^{18}$

\subsubsection{Capital Levies in the Transition to Wage versus Consumption Taxes}

Return now to the statement that, in pure form, a wage tax and a consumption tax are equivalent in the steady state. Once one accounts for the transition, however, some define a consumption tax as equal to a wage tax plus a capital levy. Others dispute this definition, insisting that the two taxes should be viewed as equivalent regardless, because whether there is a capital levy is a separate question. Ultimately, this is a semantic dispute. It is helpful, nevertheless, to explain the various policy packages envisioned by the different approaches in order to understand the range of possibilities and clarify subsequent discussion.

Consider the following four schemes: ${ }^{19}$

1. Consumption tax without capital levy: For example, this scheme would tax all wages and withdrawals from qualified accounts and allow a deduction for all contributions into qualified accounts (one of the standard forms proposed for a consumption tax). Note that pre-enactment capital, under such a scheme, would effectively receive an immediate deduction when moved into one of the newly created qualified accounts.

2. Consumption tax with capital levy: For example, modify the prior scheme so that

not the quantity of future consumption itself.

${ }^{18}$ For further analysis of how some of these factors affect possible transitions to a consumption tax, see, for example, Gentry and Hubbard (1997), Sarkar and Zodrow (1993), Seidman (1997), and Zodrow (2002).

${ }^{19}$ In addition to previously mentioned simplifications, debt is ignored. See note 28. 
contributions to qualified accounts would only be deductible if from currentlytaxed wages (or from transfers from other qualified accounts) and, in addition, tax would be imposed on withdrawals from non-qualified accounts (including the use of proceeds from sales of assets not in qualified accounts or the use of cash not attributable to a withdrawal from a qualified account).

3. Wage tax without capital levy: For example, a wage tax could be levied on all post-enactment wages (period).

4. Wage tax with capital levy: For example, a wage tax could be supplemented by a tax on all spending not from qualified accounts, which would be accounts that could only receive deposits from previously-taxed wages. (Such a scheme might back up a wage tax to deal with evasion problems.)

Clearly, the steady-state equivalence of wage and consumption taxation carries over to the transition if one compares schemes 1 and 3 or schemes 2 and 4 . If one compares 2 and 3 , the result is that, in transition, the consumption tax equals a wage tax plus a capital levy, and if one compares 1 and 4, in transition the wage tax equals a consumption tax plus a capital levy. Although some schemes may be easier to implement than others, or some may seem more "natural," it is clear that nothing in logic links a capital levy to a consumption tax or a wage tax and that, as a rough cut, the merits or demerits of a capital levy as such should determine whether it should be imposed. ${ }^{20}$

\subsubsection{Transition to a Consumption Tax versus Elimination of an Income Tax}

Although the motivation for consideration of the transition to a consumption tax is in substantial part that it might replace some or all of the existing income tax, the discussion of transition per se has thus far only referred to the implementation of a consumption (or wage) tax, each with or without a capital levy. Nevertheless, the idea that a transition capital levy would result in double taxation - taxing under a newly-enacted consumption tax savings that (generally, to the extent of pre-enactment basis) had already been taxed under an income tax - links the capital levy to the fact that transition is from an income tax..$^{21}$

One of the many lessons of Bradford's (1996a, 1996b, 1998) contributions, however, is that in important respects the capital levy should be associated with the imposition of a

${ }^{20}$ Regarding administration, note for example that scheme 2 , a consumption tax with a capital levy, can be implemented by imposing a sales tax or VAT and not providing any offset for preexisting assets.

${ }^{21}$ Even here, the linkage in part depends on the manner in which the preexisting income tax operates. For example, if the Auerbach-Jorgenson (1980) system of depreciation were employed, under which there is immediate expensing in an amount equal to the present discounted value of the depreciation deductions that otherwise would be allowed, individuals would have no basis in such assets at the time of transition and hence no basis would be eliminated by moving to a consumption tax that provided no relief for pre-enactment basis. 
consumption tax of the type in scheme 2 , without regard to repeal of a preexisting income tax. ${ }^{22}$ This is most easily seen by the imposition of a consumption tax of the type in scheme 2 in an economy with no preexisting tax: The value of old capital would be reduced, and relatedly the prospect of the imposition of such a tax would have anticipatory effects, namely, increasing preenactment consumption, inducing capital flight, and encouraging other activities that reduced (at least apparent) capital holdings at the time of enactment. Bradford vividly illustrates the point with his familiar example of the retailer with an inventory of canned tomato juice. Under an operating cash-flow consumption tax, purchases of inventory would be deductible and sales out of inventory fully taxable. But inventory held at the moment of enactment would be subject to a capital levy under a type- 2 scheme. (Note that this levy on inventory is identical to that described in section 3's second example of a Pigouvian tax that was previously levied on purchases of inputs but is reformed to be levied on the use of inputs.)

Another way to see the point, following Kaplow (1995), is to decompose the transition from an income tax to a consumption tax into two steps: (A) transition from an income tax to a wage tax (under scheme 3, with no capital levy), and (B) transition from a wage tax to a consumption tax (of type to be determined). Step (A), by construction, involves no capital levy. If the preexisting income tax was a pure, accrual income tax, then the net effect of step (A) is that all capital income would be taxed up until the moment of transition, after which it would no longer be subject to tax. The only anticipation effect would be to increase investment (savings) ex ante, since the future returns that are in the post-enactment period would be treated more favorably. (That is, the reduction of intertemporal distortion would to an extent precede enactment.)

Step (B), the move from a wage tax to a consumption tax, involves no steady-state difference. In the simple world depicted at the outset of this subsection, it is a pure accounting change. One could choose to have a capital levy, by moving to a consumption tax under scheme 2 , or one could choose not to, using scheme 1. (One could also have a negative levy, by distributing funds to owners of preexisting capital, if one wished.) In addition, one could contemplate the move from a consumption tax to a wage tax and ask whether that transition should be the occasion for a capital levy or for bestowing a windfall.

\subsection{Evaluation of a Consumption Tax Transition Capital Levy}

\subsubsection{Repetition}

Even though the concern about repetition is the most discussed potential limitation of a capital levy, there has been little attention to whether the capital levy that might accompany transition to a consumption tax is one that would generate expectations of likely repetition. An

${ }^{22}$ As Bradford (1998) emphasizes, the Johansson-Samuelson theorem indicates that, under an accrual income tax, changing rates pose no special problems; thus repeal of such an income tax (i.e., changing the rate from the existing positive level to zero) has no effect on asset values. Accordingly, the capital levy, if any, should be associated with transition to a consumption tax. 
exception is Weisbach (2003), who explains what is probably implicitly on the minds of many: that one would only replace the income tax with a consumption tax once, so repetition may be unlikely. An important caveat is that if, say, a consumption tax were implemented at a more modest level, merely to raise additional revenue or to replace only part of the income tax or payroll tax, there may well be an expectation of repetition. Another point is that rate increases under a consumption tax produce similar effects (a point elaborated in subsection 4.4); however, if most revenue were raised under a consumption tax, this problem may be limited, except to the extent taxes were generally rising over time (perhaps to fund continued growth in social insurance obligations).

However, the more it is recognized that a capital levy is optional under a consumption tax, the less sanguine one can be about the expectations of repetition that might accompany a consumption tax transition capital levy. See Shaviro (2000). Consider, for example, that some economists, such as Auerbach (2005) and Kotlikoff (2005), have publically advocated the virtues of the capital levy as an - perhaps the most - important reason to move to a consumption tax. Various consumption tax proposals, such as the plan in Blueprints (Bradford and U.S. Treasury 1984) and the USA tax proposal in the mid-1990's, have contained significant, even if incomplete, transition relief. Undoubtedly, there would be strong political pressure from those who stood to lose most by a capital levy to provide relief. If, in the end, a consumption tax with a transition capital levy were enacted, it would be widely understood that the capital levy was a major motivation for the policy change and that, when directly confronted with the prospect of a substantial capital levy, the balance of political forces and strength of anti-capital-levy social norms were such that a capital levy was on-balance politically attractive. In such circumstances, it is hardly clear why future prospective investors would believe that repetition (albeit under a different guise) was unlikely. ${ }^{23}$

\subsubsection{Anticipation}

Following the discussion in subsection 2.2, it seems that, in a modern democracy, substantial time would elapse from initial contemplation of a consumption tax transition capital levy to its ultimate enactment. The path from discussion by academics to broader public and political consideration to the formulation of proposals to lobbying, refinement, and ultimate enactment could not be expected to be brief. One possibility is that, until the very end, proposals could be in the form of scheme 1, without a capital levy, with a last-minute amendment shifting to scheme 2, with a capital levy. This approach - if truly unexpected, ultimately successful, and not altered shortly after, once the surprise had been discovered - would avoid the anticipation

\footnotetext{
${ }^{23}$ On the other hand, if a transition were made to a consumption tax without a capital levy (scheme 1) and for administrative reasons there were idiosyncratic imperfections that resulted in gains to holders of some types of assets and losses to others, the problem would be more attenuated both in magnitude and in kind. Even assuming individuals anticipated that future reforms might also produce various mismatches, if they were largely random there would be little incentive effect. (Isolated anticipation effects would, however, arise to the extent that particular deviations were expected.)
} 
problem, but this chain of events seems unlikely. ${ }^{24}$

In addition, many consumption tax proposals, like other major tax reforms, contemplate a phase-in to ease the transition in various respects. Although traditionally objected to on grounds of additional complexity and deferring the benefits of reform, in the present setting one must add the substantial interim distortion that would result. ${ }^{25}$ See, for example, the simulations in Howitt and Sinn (1989) and also those in Auerbach and Kotlikoff (1987) on early announcement of reforms.

The forms of anticipatory activity would obviously depend on the length of time and various particulars of the consumption tax transition capital levy. Regarding the latter, the ability to detect and prevent capital flight or cash hoarding could reduce pre-enactment avoidance. Also relevant are various particulars of how the consumption tax would operate. For example, if consumer durables were treated using a prepayment approach, under which purchases would not be deductible as investment and sales proceeds would be exempt, there may be a substantial incentive for individuals to purchase consumer durables before enactment. The treatment of debt, tax-exempt institutions and foreigners (who may enter into transactions ex ante with taxable individuals and entities), and other structural features could also have a substantial impact on the extent of avoidance. It should be emphasized that avoidance activity is doubly costly: It both is distortionary and reduces the amount of capital to which the transition capital levy would apply. (Note that if substantial avoidance is cheap and easy, such as through financial manipulations, the levy may largely be circumvented at only modest aggregate efficiency cost; nevertheless, the likely distortion per unit of revenue would be substantial in such a case.)

Further, note that, if the time period is sufficiently long, the anticipation effects will be highly detrimental even without any special maneuvering. After all, the straightforward incentive is to greatly increase current consumption at the expense of investment, a behavioral response that cannot readily be outlawed after the fact. Well in advance of any expected enactment, long-term investment projects would be eschewed (with the effect increasing at the time to enactment approaches), and closer to the effective date short-term projects would be discouraged as well.

\subsubsection{Distribution}

As indicated in subsection 2.3, a capital levy tends to have favorable distributive effects

\footnotetext{
${ }^{24}$ Auerbach and Hines (1987) find that a perfect foresight model is, in most cases, much closer to a myopic model in explaining investor behavior in anticipation of U.S. tax reforms. Furthermore, the tax changes they study probably had briefer lead times and less phasing in than would be likely the case for a tax reform of the scope of replacing the income tax with a consumption tax.

${ }^{25} \mathrm{By}$ the same logic, anticipation problems would be reduced if the reform could be made effective retroactively, reaching back to consumption substantially prior to enactment. This outcome does not seem politically likely.
} 
(without which it would have no appeal because one could instead change the grant component of the income tax, raising the same revenue and avoiding the problems of anticipation and repetition). That appeal, however, is limited by the imperfect relationship between capital holdings at any moment in time and underlying earnings ability (suggesting the possible superiority of a retrospective earnings tax over a capital levy). The single greatest problem is due to the lifecycle effect, a consequence of which is that a capital levy redistributes from middlelifetime-income older individuals to younger individuals with no (or negative) savings but high expected lifetime income. ${ }^{26}$

As a first approximation, a consumption tax transition capital levy fits this mold because, as subsection 4.1.3 explains, the levy is best understood as caused by the introduction of a consumption tax of the type in scheme 2 rather than repeal of the income tax, and this levy indeed applies to old capital. Nevertheless, the actual incidence will be influenced by numerous complications pertaining to the nature of the consumption tax that is ultimately enacted and the operation of a preexisting income tax, as discussed briefly in subsection 4.1.1 and further in some of the references cited therein. The incidence will also depend on the extent of relief that is provided and, some would argue, on the implicit compensation provided by the higher net-of-tax return to capital under a consumption tax, the subjects of subsections 4.3 and 4.5.

\subsection{What Counts as Full Relief?}

This subsection inquires into the appropriate nature of transition relief taking as given that the objective is to avoid a capital levy (whether this objective is appropriate having been the subject of subsection 4.2). This question has been analyzed, for example, in Bradford (1996a, 1996b), Kaplow (1995), and especially Bradford (1998).

Initially, consider the transition from a pure, accrual income tax (i.e., one that immediately recognizes all gains and losses) to a consumption tax - or from a no-tax regime to a consumption tax. If one wished to avoid any capital levy, it would be necessary in some fashion to avoid applying the new consumption tax to the full market value of pre-enactment assets. This might be accomplished by allowing individuals an immediate deduction for the full amount, which would entail refunds for many. (This formulation imagines, for simplicity, a flat-rate tax with refundability of losses.) Alternatively, deductions might be allowed over time, as long as the not-yet-deducted sum gave rise to a supplemental, ongoing deduction equal to the product of that amount and the interest rate, which would preserve the value of the write-offs. ${ }^{27}$ (In either case, it is important to coordinate the treatment of pre-enactment debt, an important dimension

\footnotetext{
${ }^{26}$ For a more detailed analysis of the incidence of a transition to a consumption tax, see Gentry and Hubbard (1997).

${ }^{27}$ The former entails a greater short-run revenue loss, although there is no difference in the effect on the present value of revenue. Likewise, without regard to any capital levy, moving to a consumption tax rather than to a wage tax delays the collection of revenue on earnings that are saved. In either case, it is natural to contemplate adjustments to national debt to accommodate the change in the timing of government revenue.
} 
that will not be discussed separately here. ${ }^{28}$ )

Suppose instead that the starting point for the transition to a consumption tax is an income tax more like the existing one, in which basis is often less than market value for a variety of reasons. ${ }^{29}$ Then the question arises whether "full relief" entails protection of the entire market value at the effective date of the consumption tax or merely the basis of preexisting assets. It might appear that the answer is the latter, for protecting basis seems both necessary and sufficient to avoid "double taxation." However, this view is incomplete.

To analyze this problem, it is helpful to return to the two-step decomposition introduced in subsection 4.1.3, in which we consider (A) a transition from the income tax to a (scheme-3) wage tax, followed by (B) a transition from the wage tax to a consumption tax. Regarding step (A), examine first the case in which basis is below market value on account of unrealized capital gains. Under a wage tax, the capital gains will never be taxed. Hence, the question arises whether, in ending the income tax regime, there should be a tax on unrealized gains. On one hand, this would be more in accord with the income tax "ideal." However, that definitional ideal does not per se have normative force, and even if it previously did, it is not clear why this would remain so when the income tax is being repealed. If a positive view is taken of capital levies, this gain should be taxed, but similar analysis applies to the extent of basis as well. If instead one takes a full anticipation view, the prospect that unrealized capital gains would be never be taxed due to transition to a wage tax would reduce the effective tax rate on investment ex ante, which would be desirable if the tax on capital income is overall taken to be distortionary, a likely motivation for substituting a wage tax. ${ }^{30}$ (There would also be costs due to increased lock-in in

${ }^{28}$ One can interpret the discussion in the text as applicable to net assets, which would be appropriate for a cash-flow personal consumption tax. See, for example, Kaplow (1995). (Amounts owed could be viewed as negative assets, one could provide negative basis, and so forth.) However, some consumption tax schemes have a real base - i.e., one that excludes financial transactions - in which the proper treatment of debt (a type of financial asset) may differ. The significance of this point can be appreciated through examples offered in Bradford (1996a, 1996b, 1998, 2004) in which a business purchases inventory, financed fully by borrowing, just prior to enactment of a consumption tax. Under some variations, the treatment of the businesses inventory and borrowing would be offsetting, in which case different transition methods would effect whether there was a capital levy on the lender. Bradford also explores the related point: Whether certain forms of consumption taxation (notably, a sales tax or VAT) will be accommodated by a one-time easing of monetary policy so that price levels increase by the amount of the tax; the degree of adjustment will affect the incidence of the transition between borrowers and lenders (if prices rise, repayment of principal stated in nominal terms will be with dollars of lower real value).

${ }^{29}$ The analysis for basis in excess of market value is similar. Of course, due to the nature of actual depreciation schedules and the strategic realization of losses, this case is less important.

${ }^{30}$ It might be noticed that the argument in the text suggests that retroactive relief for capital taxation would be efficient if indeed such relief would be anticipated. This point is generic to many transition settings. Thus, in the first example in section 3 involving a Pigouvian 
the interim.)

Second, examine the case in which the below-market-value basis is due to expensing or accelerated depreciation under the original income tax. To that extent, consumption tax treatment is already provided. Accordingly, with respect to this gap between basis and market value, we have a situation akin to a transition from a consumption tax to a wage tax. As suggested previously, this should be viewed as a pure accounting change. Avoiding any levy (in this case, a negative one, that is, a windfall) would require ultimate taxation of the difference between market value and basis.

Third, consider retirement savings that, under the pre-existing income tax, were never subject to tax. In this case, basis is zero and consumption tax treatment has been provided with regard to the entire amount. Accordingly, to effectuate a transition to a wage tax that exacts no positive or negative levy would necessitate taxation.

Regarding step (B), the transition from a wage tax to a consumption tax, we have, like with the reverse move just mentioned, a pure accounting change. As previously suggested, if one does not wish to make such an event the moment to impose a capital levy, the market value of pre-enactment capital should not be subject to the consumption tax. Note that, considering this move in isolation, the concept of basis does not arise since basis has no role under a pure wage tax system.

If we combine the results from steps (A) and (B), thereby returning to the transition from an actual income tax to a consumption tax, we see that there is a reason to protect only basis, not full market value, in some cases, notably to the extent basis falls short of market value due to consumption-tax-like treatment of prior earnings. ${ }^{31}$ In light of the analysis in subsection 4.1.3, it should not be that surprising that the reason for protecting less than full market value in some instances has to do with repeal of the income tax (in particular, hypothetically replacing it with a wage tax) rather than with introduction of a consumption tax (or using it to replace a wage tax).

Having stated what would constitute full relief, it is easier to appreciate the extent of the consumption tax transition capital levy if no relief is to be provided. For retirement accounts, expensed assets, and some others (see note 31 on consumer durables), since no basis protection is required to provide full relief, the failure to provide any relief would not constitute a capital levy. More broadly, because the current income tax is already like a consumption tax in many respects, transition to a scheme- 2 consumption tax would entail a more limited capital levy than might

tax, it would be efficient for the tax to apply to external harm generated prior to enactment, again on the assumption that such a transition regime would be anticipated. See Kaplow (1986, 1987, 2003).

${ }^{31}$ Another interesting case involves consumer durables, if a prepayment method is to be adopted under a consumption tax. No basis protection would be required because the proceeds from sales of such assets will be tax exempt. 
first appear to be the case. ${ }^{32}$

\subsection{Rate Changes under Consumption Taxation}

Return yet again to Bradford's (1996a, 1996b, 1998) important lesson that the capital levy that arises when making a transition from an income tax to a (scheme-2-type) consumption tax is due to the introduction of the consumption tax rather than repeal of the income tax. This point carries the implication, which he also emphasized, that rate changes under such a consumption tax also cause capital levies. After all, introduction of a $25 \%$ consumption tax is equivalent to raising the rate from $0 \%$ to $25 \%$. If that entails a substantial capital levy, then raising the rate from $25 \%$ to $30 \%$ would likewise constitute a capital levy, although a much smaller one. Similarly, reducing the rate from $25 \%$ to $20 \%$ would entail a negative levy, that is, a windfall to existing capital. ${ }^{33}$

Although many had examined how one could accomplish the initial transition to consumption tax with no capital levy (scheme 1), little attention had been devoted to how one might avoid (positive and negative) capital levies due to rate changes once a consumption tax was in place - assuming indeed that such was desirable. The most comprehensive treatment of the subject is in Bradford (1998). See also Boadway and Bruce (1984) and Weisbach (2003).

The basic approach (actually, one of two variants that Bradford offers) marries two ideas. ${ }^{34}$ First, under an income tax, provision of economic depreciation renders income taxation, including rate changes, neutral with regard to asset values (the Johansson-Samuelson theorem). Second, the difference between an income tax and a consumption tax in steady state is due to the taxation of the time value of money (the return to waiting) under the former. Therefore, if one provides an ongoing, supplemental deduction equal to basis times the interest rate, this taxation would be eliminated. Accordingly, Bradford explains, the aforementioned alternative transition scheme of providing individuals basis that is deducted over time, with a supplemental and ongoing deduction for interest on the basis account, can be deployed so that consumption tax rate changes produce no capital levy (positive or negative).

Specifically, all assets - including those acquired under the consumption tax regime would be subject to economic depreciation, combined with an additional annual deduction for interest on undepreciated basis, rather than providing for expensing, which is normally

\footnotetext{
${ }^{32}$ Debt, if also not subject to transition provisions, further complicates the story. See also note 28.

${ }^{33}$ Changing rates under a consumption tax - or under a wage or income tax - also results in a capital levy (negative for rate decreases) with regard to human capital, which is generally ignored here.

${ }^{34}$ Bradford's other approach is to allow immediate expensing but also to provide a supplemental credit (which would be negative for a rate decrease) at the time the consumption tax rate changes, in an amount equal to the product of the market value of assets and the change in the tax rate.
} 
envisioned for a cash-flow consumption tax. If tax rates remain constant, these schemes are equivalent since the deductions provided under each have the same present value. If rates change, however, the augmented depreciation scheme avoids any capital levy. The reasoning parallels that of providing protection equal to market value when a consumption tax is implemented. When the consumption tax rate, say, increases, preexisting capital might otherwise be subject to a partial capital levy proportional to its market value. However, under the proposed scheme, there would exist a tax basis equal to market value at all times, giving rise to future deductions at the now-higher consumption tax rate. Since the present value of those remaining deductions (including the supplemental deductions for interest on basis) would equal the market value of the asset at the time of the rate increase, full protection would be provided. Analogously, if rates fell, the future deductions would be at the now-lower tax rate, thereby avoiding a negative capital levy.

Bradford demonstrated that this approach works in theory but also understood that it would be imperfect in practice. Providing true economic depreciation requires accurate prediction or contemporaneous measurement of changes in value. This is difficult when values fluctuate and especially challenging with regard to intangible assets. Indeed, as Bradford (2004) notes, many view such problems as the Achilles heel of the income tax. Because avoiding the need for such measurements is thus one of the principle reasons to move to a consumption tax, retaining such a system post-transition may seem unappealing. ${ }^{35}$ It should be emphasized, however, that there would be a lower error cost if the accuracy of depreciation or other adjustments for changes in market value only mattered to the extent of rate changes. For example, a rate change of, say, $3 \%$ would only have one-tenth the impact of introduction of a $30 \%$ consumption tax (and, to the extent that pertinent distortions are proportional to the square of the tax rate, only one hundredth of the efficiency consequence). The capital levy would be limited not only by the size of the rate change but also by the magnitude of the measurement error (specifically, it would be equal to the product of the two). In other words, ordinary rate changes reflecting fluctuations in revenue needs may usually be of modest significance to begin with, and their impact could further (if not fully) be mitigated, if such a scheme were worth the administrative cost.

\subsection{Is Pre-Enactment Capital Compensated through Higher Returns?}

Suppose that an income tax is replaced by a consumption tax that contains a transition capital levy (scheme 2). Suppose further that, as a result of removing the tax burden on capital income, the net-of-tax return on capital increases. ${ }^{36}$ This latter effect produces a benefit that is

\footnotetext{
${ }^{35}$ Relatedly, because it is so difficult to provide true economic depreciation under an income tax, the Johansson-Samuelson theorem does not hold in practice, and accordingly rate changes under an income tax can also result in significant (positive or negative) capital levies. See, for example, Kaplow (1987).

${ }^{36}$ At one extreme, such as in a small, open economy, the before-tax rate of return would be fixed so the net-of-tax return would rise by the full amount of the preexisting tax. At the other extreme, individuals' supply of capital is perfectly elastic at the pre-reform net-of-tax rate, so the
} 
greater for those who save more. Accordingly, some suggest that even a type- 2 scheme provides significant implicit compensation for its capital levy, rendering it unnecessary to consider type-1 consumption tax schemes that contain no levy. ${ }^{37}$ One could go further and argue that such nolevy schemes would instead provide a windfall to holders of capital because the benefit from the higher net-of-tax return would remain.

To assess this argument, it is best to begin by returning to the question addressed in section 2 of whether and why a capital levy may be beneficial or undesirable. Regarding the problem of repetition, if indeed full compensation resulted there would be no reason to fear recurrence of the combined policy. However, as discussed in subsection 4.2.1, the concern is not that individuals would anticipate repetition of the transition from an income tax to a consumption tax. Instead, the fear is that, since the capital levy can be separated from the pure, steady-state tax reform, the fact that a levy is imposed may raise the prospect that subsequent levies (in different forms) would be enacted. Nevertheless, if indeed the increased return approximated full compensation, the precedent set by the transition would be different, so repetition may be much less of a problem.

It is familiar, however, that the nature of "compensation" is highly uneven, due primarily to lifecycle effects (but also to differences in preferences and other factors). ${ }^{38}$ Notably, young individuals with no savings receive the maximal benefit from higher future returns but bear none of the levy. Older individuals with large lifecycle savings are subject to the maximal levy yet receive the least compensation (that is, for given preferences and lifetime income). The breakeven point would be at some age in between. There is a substantial intergenerational redistribution. ${ }^{39}$ But, importantly, the extent of what is given up by older individuals depends on the amount of their accumulated capital, so the compensation does not seem to be of a nature that would substantially erase the repetition concern.

For similar reasons, the anticipation problem is alleviated even less. Because the capital levy applies to the amount of capital one holds at the time of transition, the incentive to increase consumption and reduce investment remains. The basic problem is that the extent of the capital levy depends on past savings whereas the benefit depends on future savings. Of course, the two

market rate of return would fall by the amount of the tax, resulting in no change in the net-of-tax return. The discussion in the text is based on the premise that the result would be somewhere in between. See, for example, Bradford (1996a, 1996b).

${ }^{37}$ See, for example, Graetz (1979). Another, related factor bearing on the extent of implicit compensation is that transitions may influence relative asset prices, differentially affecting old capital.

${ }^{38}$ To the extent that implicit compensation arises through changes in asset prices or other simultaneous tax reforms (for example, repeal of the corporate income tax) that are favorable to old capital, the relation of compensation to direct loss would be closer.

${ }^{39}$ It should also be noted that there are other means of influencing the intergenerational distribution - such as debt policy and social security - that are not a function of the extent of capital one chooses to accumulate. 
are related, in that individuals would not fully dissave before an anticipated transition and then fully restore their savings to the lifecycle optimum immediately thereafter (unless this could be accomplished through certain forms of financial avoidance activity). Although this point moderates the impact of an anticipated capital levy, it would do so even if there were no increase in the net-of-tax return. In sum, the implicit compensation does not substantially eliminate the adverse anticipation incentives due to the prospect of a capital levy.

Finally, consider distribution, which is the factor that seems closest in spirit to the loosely specified notions of equity that are often invoked in debates about the consumption tax versus the income tax and the problem of transition and compensation. As discussed in subsections 2.3 and 4.2.3, if the levy were distributionally unattractive, it probably should be avoided, since concerns about anticipation and repetition could only make matters worse. However, it was suggested that the distributive effects are likely to be attractive. To the extent that is the case, it seems odd that on equity grounds one would desire compensation, since perfect compensation would precisely destroy the beneficial distributive effects.

Here again, the lifecycle mismatch (and others) is pertinent. It was explained that a capital levy, such as that entailed by moving to a scheme- 2 consumption tax, was only loosely correlated with underlying (lifetime) earning ability, and accordingly may well be distributively dominated by other regimes. Interestingly, the deviation between desired distributive effects and the capital levy mirrors the gap between the incidence of the levy and the purported compensation. The levy was only moderately desirable distributively primarily because it taxed the old too much and the young too little. The presence of compensation that is greatest for the young and least for the old does not improve the situation.

There is also an important conceptual question concerning the sense in which the enhanced net-of-tax return should be viewed as compensation for a capital levy. To see the problem, consider again, as suggested in Kaplow (1995), the two-step decomposition of the transition from an income tax to a consumption tax, with step (A) being the (hypothetical) move from an income tax to a wage tax and step (B) that from a wage tax to a consumption tax. Note that it is step (A) that is responsible for the increase in the net-of-tax return. If one were in fact simply moving to a wage tax, one could ask whether this benefit should be considered a windfall of sorts. To do so assumes that there is some sort of natural entitlement to the net-of-tax return under an income tax and that any deviation is distributively inappropriate. It is hard to identify why this should be so. Indeed, if a motivation for the reform is to eliminate intertemporal distortion, one might conclude the opposite. In a simple world, the move would constitute a Pareto improvement. ${ }^{40}$

The capital levy is solely attributable to step (B) - assuming that one moves from a

${ }^{40}$ Specifically, the argument of Atkinson and Stiglitz (1976) shows that the move is welfare increasing (with weak separability and identical preferences) and the generalization in Kaplow (2006) demonstrates how one can implement the move so as to generate a Pareto improvement (by means of a distribution-neutral reform). 
scheme- 3 wage tax to a scheme- 2 consumption tax - and that step produces no compensation. This point further suggests the lack of nexus between the capital levy and the compensation. This conclusion is also illustrated by comparing two otherwise-identical individuals, one who saves a moment before enactment and the other a moment after; the capital levy hits only the first but the compensation is received by both.

The same ideas can also be illustrated with a different example. ${ }^{41}$ Suppose that in the status quo there is a differential tax on chocolate. One day, it is repealed on account of its inefficiency (in distorting consumption between chocolate and vanilla). Would it be appropriate to accompany this transition with a one-time tax on chocolate lovers, and in particular, a tax that was an increasing function of age (perhaps it would be a function of lifetime chocolate consumption to date)? Such a suggestion would seem perverse for two reasons: The benefits of the reform are falling with age (fewer years over which to enjoy additional chocolate), and, perhaps more to the point, it is hard to see why elimination of the distortionary tax calls for any redistribution between chocolate- and vanilla-lovers in the first place (even without regard to the opposite lifetime incidence of the benefits of the repeal and the costs of the redistributive levy).

\section{Literature on Dynamic Models of Taxation}

\subsection{Transition Simulations}

In order to assess the effects of transition from an income tax to a consumption or wage tax on savings, growth, efficiency, and the inter- and intragenerational distribution of income, researchers have built dynamic simulation models. Most well known is the work in Auerbach and Kotlikoff $(1983,1987)$ and Auerbach, Kotlikoff, and Skinner (1983). Subsequent analyses providing greater detail along various dimensions include Altig et al. (2001), Auerbach (1996, 2007), Sarkar and Zodrow (1993), and Zodrow (2002). See also the discussions in Bernheim (2002) and Shaviro (2000).

Pertinent results are amply illustrated by the simulations in the various work of Auerbach, Kotlikoff, and Skinner. In basic simulations, moving to a consumption tax raises steady-state welfare by $6 \%$ whereas moving to a wage tax reduces it by $4 \%$. The explanation is that the former reform involves a scheme- 2 consumption tax - with a capital levy - and the latter involves a scheme-3 wage tax - without a capital levy. Also, as suggested in subsection 4.3, moving from an income tax to that type of wage tax may also entail a windfall to the extent assets received consumption-tax-like treatment under the income tax. With a positive capital levy, taxes in the future can be forever lower, so consumption and welfare can be higher. With in essence a negative capital levy, future taxes must be higher, which reduces consumption and

${ }^{41}$ Yet another perspective on the problem is provided by considering the fact that an increase in the net-of-tax return constitutes a change in relative prices (between consumption in different periods) and thus presents a price index problem, wherein welfare comparisons are made more difficult. This angle is pursued in Kaplow (1986, pp. 611-12, n. 322). 
welfare.

In this work and the commentary thereon - though not necessarily in the minds of all who may view the bottom-line results - it is well understood that these steady-state effects are substantially due to the differences in capital levies. (For example, Auerbach, Kotlikoff, and Skinner (1983, p. 81) state in their introduction that "It is this element of lump-sum taxation, and not the exemption from taxation of capital income per se that is crucial to the achievement of an efficient tax reform.") Furthermore, it is known that the steady-state effects are opposite for those in generations subject to the transition. Older generations subject to the consumption tax transition capital levy lose (though future generations gain), and the same groups gain under the wage tax transition capital give-away (though future generations lose). When the authors introduce the device of a lump-sum (intergenerational) redistribution authority to offset the intergenerational redistribution, much of the difference between the two types of transition disappears. $^{42}$

These simulations provide quantification of the (positive or negative) capital levy under various scenarios. They are not, however, designed to illuminate issues pertaining to repetition or anticipation: Most such simulations implicitly assume that there are no effects of either type. Some do consider anticipation and find as one would expect that the effect is adverse for transition to a (scheme-2) consumption tax but favorable for moving to a (scheme-3) wage tax, to an extent offsetting and possibly reversing the main results. One should also note the aforementioned simulation results of Howitt and Sinn (1989), who show that a substantial phasein of a consumption tax can cause sufficient distortion due to anticipation effects during the transition to outweigh the otherwise positive effects of the capital levy. ${ }^{43}$ Overall, given the conceptual focus of the present essay, the primary relevance of this work is to illustrate concretely and provide some quantification for certain aspects of transition capital levies.

\subsection{Optimal Capital Taxation in the Long Run}

A substantial body of literature examines the optimality of capital taxation in infinitehorizon models. Representative contributions include Chamley (1986) and Judd (1985), with Auerbach and Hines (2002) and Bernheim (2002) providing recent surveys. It seems largely unappreciated, however, that these literatures can partly be understood as involving transitions from income to consumption taxation, and in particular transitions in which a sort of capital levy

${ }^{42}$ There still can be efficiency effects, depending on other changes and how the intergenerational redistribution is implemented, by comparison to the capital levy. In this regard, Bernheim (2002, p. 1195) observes: "It is natural to wonder about the sign and magnitude of pure efficiency effects when one eliminates surprise capital levies and subsidies (the third effect) by considering fully anticipated tax reforms, but [Auerbach, Kotlikoff, and Skinner] do not undertake such experiments."

${ }^{43}$ Regarding distribution, some of the more recent work devotes more attention to the matter by allowing income-based heterogeneity and attending to differential transition effects on different types of assets. 
plays a central role.

In these models, time begins with a preexisting stock of capital. The government is permitted to tax the return to capital at up to $100 \%$, and it also may tax labor income, which produces distortion. The optimum under standard assumptions has the character that capital income is taxed at $100 \%$ in initial periods, but ultimately $0 \%$ thereafter. (The duration of the $100 \%$ tax depends on the government's long-run revenue requirements, among other things, and there may be an intervening period in which an intermediate rate is employed.)

These models ignore repetition and anticipation, that is, they assume that commitment is possible and that the tax may be imposed starting at time zero. Regarding the latter, the preexisting capital stock is taken as given, which is to say, implicitly, that behavior during preceding periods during which income was earned and some if it was saved rather than consumed is taken to be unaffected by the prospect of the capital tax. Moreover, individuals are identical in these models, so distribution is moot. ${ }^{44}$

In this world, it would be optimal to employ a uniform lump-sum levy, which might raise all necessary revenue without distortion. This possibility is ruled out. In this regard, see the comments in subsection 2.3 on Ramsey-based models and also the references in notes 9 and 16 (the latter of which relate directly to the literature on capital taxation). As noted there, a capital levy may be seen as a substitute for lump-sum taxation - a perfect substitute, to the extent of the capital stock, if one can ignore repetition, anticipation, and distribution. The only difference here is that these models add the further restriction that the capital tax in any period may not exceed $100 \%$ of capital income.

At this point, the source of this part of the literature's results is apparent. Employing a $100 \%$ capital tax for a period of time is the best approximation the model will allow to a capital levy or a lump-sum tax. If revenue needs are small, one period (of perhaps less-than-100\% taxation) will suffice. If revenue needs are larger, the $100 \%$ tax should be imposed longer. In this latter case, distortion arises after time zero; hence, it is best to use a $100 \%$ rate and end the tax as quickly as possible, so effects are maximally concentrated on old capital. Were it not for the $100 \%$ cap, it is obvious that attainable welfare would be even higher because the capital tax could then be imposed entirely in the initial period, making it precisely equivalent to a pure capital levy. ${ }^{45}$ In sum, although the literature focuses on optimal capital taxation, it is useful to

${ }^{44} \mathrm{~A}$ similar phenomenon also arises in some other literature on optimal taxation, such as that showing differential commodity taxation to be optimal if it can help tax unobservable preexisting endowments. The source of the initial endowments (prior labor earnings and savings) is outside the model, or, implicitly, in periods prior to the surprise enactment of the tax regime found to be optimal.

${ }^{45}$ Although the present essay only touches upon matters of political feasibility, it seems difficult to believe that a prolonged capital income tax at a $100 \%$ rate would not be seen as tantamount to a capital levy, making it hard to understand why the former would be politically feasible and the latter not. This point is reinforced by the fact that a capital levy of a magnitude 
view some of its results as in the genre of capital levies. Accordingly, much of the analysis in this essay bears on the significance of some of the results obtained in such models.

In addition, the form of the capital levy has a property in common with the transition to a consumption tax - or to a wage tax like that in scheme 4 , in which a capital levy is included. The transition period corresponds to the first or initial periods, in which capital is taxed. The steadystate involves a pure wage (labor income) tax or consumption tax.

\section{Conclusion}

This essay focuses on the question whether the transition to a consumption tax is an opportune occasion for the imposition of a one-time capital levy. To answer this question, it is necessary to delve more deeply into the three factors that bear on the desirability of a capital levy - repetition, anticipation, and distribution - and then to consider quite explicitly how these factors apply in the context of a consumption tax transition capital levy. Consideration of each factor presented issues that previously have received limited, if any, attention. Although no conclusion can be reached without a thorough inquiry into the political economy of the situation, which is not attempted here, the present analysis provides substantial reason for caution. The anticipation problem seems particularly acute, it is hardly obvious that repetition is not a serious concern, and even if on those grounds a capital levy were desirable, it may well be that alternative policies would be distributively superior.

This essay also explored a number of subsidiary matters, including the relationship between the adoption of a consumption or wage tax and capital levies, what sort of transition relief would avoid imposition of any capital levy (if that were the objective), capital levies associated with tax rate changes and how they could be avoided, and whether the increased netof-tax return to capital as a consequence of income tax repeal should properly be viewed as compensation for a consumption tax transition capital levy. In addition, the analysis was applied to existing literatures that offer dynamic models of taxation, both those that simulate transitions to a consumption or wage tax and those that determine optimal capital taxation in the long run. In each case, capital levies were seen to be central, a reasonably familiar theme in the former body of work but one largely unappreciated in the latter.

equal to the effect of the multi-period $100 \%$ tax would be Pareto superior. 


\section{References}

Altig, David, Alan J. Auerbach, Laurence J. Kotlikoff, Kent A. Smetters, and Jan Walliser. 2001. "Simulating Fundamental Tax Reform in the United States," American Economic Review 91: 574-595.

Andrews, William D. 1974. "A Consumption-Type or Cash Flow Personal Income Tax," Harvard Law Review 87: 1113-1188.

Atkinson, Anthony B., and Joseph E. Stiglitz. 1976. “The Design of Tax Structure: Direct Versus Indirect Taxation," Journal of Public Economics 6: 55-75.

Auerbach, Alan J. 1996. "Tax Reform, Capital Allocation, Efficiency, and Growth, " in Henry J. Aaron and William G. Gale, eds., Economic Effects of Fundamental Tax Reform (Washington, D.C.: Brookings Institution Press), 29-81.

Auerbach, Alan J. 2005. “A Consumption Tax,” Wall Street Journal (August 25, 2005: A8).

Auerbach, Alan J. 2007. "The Choice between Income and Consumption Taxes: A Primer," in Alan J. Auerbach and Daniel Shaviro, eds., Key Issues in Public Finance (Cambridge, MA: Harvard University Press), forthcoming.

Auerbach, Alan J., and James R. Hines, Jr. 1987. "Anticipated Tax Changes and the Timing of Investment," in Martin Feldstein, ed., The Effects of Taxation on Capital Accumulation (Chicago: University of Chicago Press), 163-196.

Auerbach, Alan J., and James R. Hines, Jr. 2002. "Taxation and Economic Efficiency," in Alan J. Auerbach and Martin Feldstein, eds., Handbook of Public Economics, vol. 3 (Amsterdam: North-Holland), 1347-1421.

Auerbach, Alan J., and Dale Jorgenson. 1980. "Inflation-Proof Depreciation of Assets," Harvard Business Review 158: 113-125.

Auerbach, Alan J., and Laurence J. Kotlikoff. 1983. "National Savings, Economic Welfare, and the Structure of Taxation," in Martin Feldstein, ed., Behavioral Simulation Methods in Tax Policy Analysis (Chicago: University of Chicago Press), 459-493.

Auerbach, Alan J., and Laurence J. Kotlikoff. 1987. Dynamic Fiscal Policy (Cambridge, UK: Cambridge University Press).

Auerbach, Alan J., Laurence J. Kotlikoff, and Jonathan Skinner. 1983. "The Efficiency Gains from Dynamic Tax Reform,” International Economic Review 24: 81-100.

Bernheim, B. Douglas. 2002. "Taxation and Saving," in Alan J. Auerbach and Martin Feldstein, ed., Handbook of Public Economics, vol. 3 (Amsterdam: Elsevier), 1173-1249. 
Boadway, Robin, and Neil Bruce. 1984. "A General Proposition on the Design of a Neutral Business Tax," Journal of Public Economics 24: 231-239.

Bradford, David F. 1986. Untangling the Income Tax (Cambridge, Mass.: Harvard University Press).

Bradford, David F. 1996a. "Consumption Taxes: Some Fundamental Transition Issues," in Michael J. Boskin, ed., Frontiers of Tax Reform (Stanford: Hoover Institution Press), 123150 .

Bradford, David F. 1996b. Fundamental Issues in Consumption Taxation (Washington: AEI Press).

Bradford, David F. 1998. "Transition to and Tax-Rate Flexibility in a Cash-Flow-Type Tax," in James Poterba, ed., Tax Policy and the Economy, vol. 12 (Cambridge, Mass.: MIT Press), 151-172.

Bradford, David F. 2004. The X Tax in the World Economy: Going Global with a Simple, Progressive Tax (Washington: AEI Press).

Bradford, David F., and U.S. Treasury Tax Policy Staff. 1984. Blueprints for Basic Tax Reform, $2^{\text {nd }}$ ed. (Arlington, VA: Tax Analysts).

Chamley, Christophe. 1986. "Optimal Taxation of Capital Income in General Equilibrium with Infinite Lives,” Econometrica 54: 607-622.

Eichengreen, Barry. 1990. "The Capital Levy in Theory and Practice," in Rudiger Dornbusch and Mario Draghi, eds., Public Debt Management: Theory and History (Cambridge, UK: Cambridge University Press), 191-220.

Feldstein, Martin S. 1978. "The Welfare Cost of Capital Income Taxation," Journal of Political Economy 86: S29-51.

Fischer, Stanley. 1980. "Dynamic Inconsistency, Cooperation and the Benevolent Dissembling Government," Journal of Economic Dynamics and Control 2: 93-107.

Friedman, James W. 1971. “A Non-cooperative Equilibrium for Supergames,” Review of Economic Studies 38: 1-12.

Gentry, William M., and R. Glenn Hubbard. 1997. "Distributional Implications of Introducing a Broad-Based Consumption Tax," in James M. Poterba, ed., Tax Policy and the Economy, vol. 11 (Cambridge, Mass.: MIT Press), 1-47.

Grossman, Herschel I., and John B. Van Huyck. 1988. "Sovereign Debt as a Contingent Claim: Excusable Default, Repudiation, and Reputation," American Economic Review 78: 1088- 
1097.

Graetz, Michael J. 1979. "Implementing a Progressive Consumption Tax," Harvard Law Review 92: 1575-1661.

Howitt, Peter, and Hans-Werner Sinn. 1989. "Gradual Reforms of Capital Income Taxation," American Economic Review 79: 106-124.

Judd, Kenneth L. 1985. "Redistributive Taxation in a Simple Perfect Foresight Model," Journal of Public Economics 28:59-83.

Kaplow, Louis. 1986. "An Economic Analysis of Legal Transitions," Harvard Law Review 99: 509-617.

Kaplow, Louis. 1987. Optimal Transition Policy: Replacing Horizontal Equity with an Ex Ante Incentives Perspective (dissertation, Harvard University Department of Economics, Cambridge, Mass.).

Kaplow, Louis. 1995. "Recovery of Pre-Enactment Basis Under a Consumption Tax: The USA Tax System," Tax Notes 68: 1109-1118.

Kaplow, Louis. 2003. “Transition Policy: A Conceptual Framework,” Journal of Contemporary Legal Issues 13: 161-209.

Kaplow, Louis. 2006. "On the Undesirability of Commodity Taxation Even When Income Taxation Is Not Optimal," Journal of Public Economics 90:

Kaplow, Louis. (Forthcoming.) The Theory of Taxation and Public Economics.

Kotlikoff, Laurence J. 2005. "The Case for the 'FairTax,'” Wall Street Journal (March 7, 2005: A18).

Kydland, Finn E., and Edward C. Prescott. 1977. "Rules Rather than Discretion: The Inconsistency of Optimal Plans," Journal of Political Economy 85: 473-491.

Roberts, Kevin. 1984. "The Theoretical Limits to Redistribution," Review of Economic Studies 51: 177-195.

Rogers, Carol Ann. 1986. "The Effect of Distributive Goals on the Time Inconsistency of Optimal Taxes," Journal of Monetary Economics 17: 251-269.

Sarkar, Shounak, and George R. Zodrow. 1993. "Transitional Issues in Moving to a Direct Consumption Tax," National Tax Journal 46: 359-76.

Seidman, Laurence S. 1997. The USA Tax: A Progressive Consumption Tax (Cambridge, 
Mass.: MIT Press).

Shaviro, Daniel. 2000. When Rules Change: An Economic and Political Analysis of Transition Relief and Retroactivity (Chicago: University of Chicago Press).

Stiglitz, Joseph E. 1987. "Pareto Efficient and Optimal Taxation and the New New Welfare Economics," in Alan J. Auerbach and Martin Feldstein, eds., Handbook of Public Economics, vol. 2 (Amsterdam: North-Holland), 991-1041.

Weisbach, David A. 2003. “Does the X-Tax Mark the Spot?” S.M.U. Law Review 56: 201-238.

Zodrow, George R. 2002. "Transitional Issues in the Implementation of a Flat Tax or a Retail Sales Tax," in George R. Zodrow and Peter Mieszkowski, eds., United States Tax Reform in the $21^{\text {st }}$ Century (Cambridge: Cambridge University Press): 245-283. 